http://jmscr.igmpublication.org/home/

ISSN (e)-2347-176x ISSN (p) 2455-0450

crossref DOI: https://dx.doi.org/10.18535/jmscr/v7i7.137

Journal Of Medical Science And Clinical Research

IGM Publication

An Official Publication of IGM Publication

\title{
Role of First and Second Trimester Uterine Artery Doppler in Prediction of Pre-Eclampsia
}

\author{
Authors \\ Dr L.V.V. Prasad MD (RD), Dr Y. Trinadh, Dr Krishna Reddy \\ Department of Radio-Diagnosis, Andhra Medical College, Visakhapatnam, India
}

\begin{abstract}
Background: Pre-eclampsia is the most important reason for maternal and fetal mortality. It affects $2-5 \%$ of pregnancies and is principally a disease of first term pregnancy1. Pre-eclampsia is due to reduced organ perfusion due to vasospasm and endothelial damage. Almost all the morbidity being due to multisystemic manifestations in many organs including brain, liver, kidney and placenta. IUGR is a complication of preeclampsia and is due to failure of normal placental invasion and development.

Materials and Methods: This is a prospective study done over a period 15 months at radiology department, Andhra medical college from April 2017 to July 2018. 100 women with singleton pregnancy attending Victoria General Hospital OPD referred to the radiology department, KGH is subjected to uterine artery Doppler along with morphology and biometry scan to study the role of uterine artery doppler in predicting pre-eclampsia.

Results: The highest incidence is noted in 21-25 years age group followed by below 20 years age group. It is more common in primigravida. 7 pregnant women developed proteinuria of which all developed preeclampsia. 10 babies developed preeclampsia of which 7 are preterm.

Conclusion: Uterine artery Doppler can be used to predict pre-eclampsia in normal people who are not having risk factors. The diastolic notch in second-trimester has the highest specificity compared to other parameters. First-trimester doppler alone has a good predictive value in predicting pre-eclampsia. Combination of first and second-trimester uterine artery Doppler is the best indicator of prediction of Preeclampsia. Women with normal impedance to flow in the uterine arteries constitute a group that have a lowrisk (negative predictive value of 96\%) of developing obstetric complications related to uteroplacental insufficiency and fetoplacental insufficiency. Uterine artery Doppler can be included in hospitals with facilities and infrastructure to identify a group of patients at risk of developing Pre-eclampsia.
\end{abstract}

\section{Introduction}

Pre-eclampsia is the most important reason for maternal and fetal mortality. It affects $2-5 \%$ of pregnancies and is principally a disease of first term pregnancy ${ }^{1}$. Pre-eclampsia is due to reduced organ perfusion due to vasospasm and endothelial damage. Almost all the morbidity being due to multisystemic manifestations in many organs including brain, liver, kidney and placenta. IUGR is a complication of pre-eclampsia and is due to failure of normal placental invasion and development.

The primary pathology is the impairment of placental perfusion, which may be attributed to abnormal placentation of maternal vascular disease. Impaired placental perfusion is believed 
to result from insufficient invasion of maternal spiral arterioles by the trophoblast early in gestation. Consequently, the crucial hemodynamic changes were seen in normal pregnant uterine vasculature - that is a shift from low volume high resistance to high volume low resistance environment does not take place ${ }^{2}$. This leads to increased vascular resistance and decreased uteroplacental perfusion. The subsequent placental ischemia may lead to production of free radicals damaging the endothelial cells. The main goals of antepartum fetal surveillance are to identify fetuses at increased risk for perinatal mortality and morbidity.

Fetal monitoring was based on diagnostic procedures, among which Doppler sonography became a top-level non-invasive method. Doppler ultrasound is capable of detecting the early placental hemodynamics $^{3,4}$. Therefore, the method can be utilized in the early detection of fetal complications.

\section{Materials and Methods}

This is a prospective study done over a period 15 months at radiology department, Andhra medical college from April 2017 to July 2018. 100 women with singleton pregnancy attending Victoria General Hospital OPD referred to the radiology department, $\mathrm{KGH}$ is subjected to uterine artery Doppler along with morphology and biometry scan after fulfilling the inclusion and exclusion criteria.

\section{Inclusion Criteria}

1. All the antenatal women of age between 18-35yrs.

2. Multigravida women with no previous history of Pre-eclampsia.

3. Pregnant ladies who gave valid consent were included.

\section{Exclusion Criteria}

1. Patients with diabetes, multiple gestations, chronic hypertension, renal disease, cardiac disease.

2. Excluded patients with unreliable last menstrual period, lost in follow up.

3. Pregnant ladies who didn't give valid consent were excluded.

\section{Results}

- 107 Patinets doppler done for pre-eclampsia prediction

- Only 100 patients came for follow up and delivered at VGH. Hence 7 patients excluded from study

- 100 Patients taken up for study

- Results, obsevation and analysis done for only 100 patients

According to our study incidence of hypertensive disorders of pregnancy during the study period of one year at Andhra Medical College, $\mathrm{KGH}$ is $15 \%$
Prevalence of Pre-eclampsia, Gestational Hypertension, IUGR $-7 \%, 8 \%$ and $10 \%$.

Of the total 100 pregnant women, $48 \%$ are in the agegroup of 21 to 25 years, $23 \%$ are in the age 
group $\leq 20$ years, $22 \%$ are in the agegroup of 26 to 30 years, $7 \%$ are in the age group $\geq 31$ years. Among 100 study population, 53 were primigravida, the incidence being $53 \%$ and the Second gravida were 30 (30\%), 17 (17\%) being Multi gravida. Most of the study population were primigravida.
Among 21 Patients of abnormal Doppler 18 Patients were induced

7 Patients had vaginal delivery, 10 Patients went for emergency LSCS, 4 Patients Went for Elective LSCS.

Table 1 : Distribution of the Bio Social Physiological Variables of the Study Population

\begin{tabular}{|l|c|c|c|}
\hline Variable & Frequency & Percent \\
\hline \multirow{3}{*}{ Parity } & Primigravida & 53 & 53 \\
\cline { 2 - 4 } & Multi gravida & 47 & 47 \\
\cline { 2 - 4 } & Total & 100 & 100 \\
\hline \multirow{4}{*}{ Albuminuria } & Absent & 93 & 93 \\
\hline \multirow{3}{*}{ Pre-eclampsia } & Present & 7 & 7 \\
\cline { 2 - 4 } & Total & 100 & 100 \\
\cline { 2 - 4 } & No & 93 & 93 \\
\cline { 2 - 4 } & Yes & 7 & 7 \\
\hline \multirow{3}{*}{ IUGR } & Total & 100 & 100 \\
\cline { 2 - 4 } & No & 90 & 90 \\
\cline { 2 - 4 } & Yes & 10 & 10 \\
\cline { 2 - 4 } & Total & 100 & 100 \\
\hline
\end{tabular}

Table 2 : Uterine Artery Doppler Findings of the Study Population - First-Trimester

\begin{tabular}{|l|c|c|c|}
\hline Doppler Findings & Frequency & Percentage \\
\hline \multirow{4}{*}{ Uterine Artery RI } & Normal & 94 & 94 \\
\cline { 2 - 4 } & Abnormal & 6 & 6 \\
\cline { 2 - 4 } & Total & 100 & 100 \\
\hline \multirow{4}{*}{ Uterine Artery PI } & Normal & 95 & 95 \\
\hline & Abnormal & 5 & 5 \\
\cline { 2 - 4 } & Total & 100 & 100 \\
\hline \multirow{3}{*}{ Uterine Artery S/D } & Normal & 94 & 94 \\
\cline { 2 - 4 } & Abnormal & 6 & 6 \\
\hline \multirow{2}{*}{$\begin{array}{l}\text { Uterine doppler Artery RI : } \\
\text { Uterine doppler Artery PI : }\end{array}$} & 6 abnormal (6\%) \\
Uterine Artery doppler S/D Ratio: & 5 abnormal (5\%) \\
Ut 6 abnormal (6\%)
\end{tabular}

Table 3 : Uterine Artery Doppler Findings of the Study Population - Second-Trimester

\begin{tabular}{|l|c|c|c|}
\hline Doppler Findings & & Frequency & Percentage \\
\hline \multirow{3}{*}{ Uterine Artery RI } & Normal & 81 & 81 \\
\cline { 2 - 4 } & Abnormal & 19 & 19 \\
\cline { 2 - 4 } & Total & 100 & 100 \\
\hline \multirow{3}{*}{ Uterine Artery PI } & Normal & 83 & 83 \\
\cline { 2 - 4 } & Abnormal & 17 & 17 \\
\cline { 2 - 4 } & Total & 100 & 100 \\
\hline \multirow{3}{*}{ Uterine Artery S/D } & Normal & 81 & 81 \\
\cline { 2 - 4 } & Abnormal & 19 & 19 \\
\cline { 2 - 4 } & Total & 100 & 100 \\
\hline \multirow{3}{*}{ Uterine Artery ED Notch } & No & 91 & 91 \\
\cline { 2 - 4 } & Yes & 9 & 100 \\
\cline { 2 - 4 } & Total & 100 & \\
\hline Uterine doppler Artery RI : & 19 abnormal (19\%) \\
Uterine doppler Artery PI : & 17 abnormal (17\%) & \\
Uterine Artery doppler S/D Ratio: 19 abnormal (19\%) & \\
Uterine Artery ED Notch : & 9 abnormal (9\%) & \\
\end{tabular}


Table 4 : Distribution of Validity Parameters of Doppler Test for Pre-Eclampsia - First-Trimester

\begin{tabular}{|l|l|l|l|}
\hline \multirow{2}{*}{ PARAMETER } & \multicolumn{3}{|l|}{ UTERINE ARTERY } \\
\cline { 2 - 4 } & RI & PI & S/D \\
\hline Sensitivity & $57.14 \%$ & $57.14 \%$ & $57.14 \%$ \\
\hline Specificity & $97.85 \%$ & $98.92 \%$ & $97.85 \%$ \\
\hline Positive Predictive Value & $66.67 \%$ & $80.00 \%$ & $66.67 \%$ \\
\hline Negative Predictive Value & $96.81 \%$ & $96.84 \%$ & $96.81 \%$ \\
\hline Sensitivity of RI : & \multicolumn{3}{|c|}{$57.14 \%$} \\
Sensitivity of PI : & $57.14 \%$ & \\
Sensitivity of S/D Ratio: & $57.14 \%$ \\
Positive Predictive value of RI: & $66.67 \%$ & \\
Positive Predictive value of PI : & $80.00 \%$ & \\
Positive Predictive value of S/D Ratio: & $66.67 \%$ &
\end{tabular}

Table 5 : Distribution of Validity Parameters of Doppler Test for Pre-Eclampsia - Second-Trimester

\begin{tabular}{|l|c|c|c|c|}
\hline \multirow{2}{*}{ PARAMETER } & \multicolumn{3}{|c|}{ UTERINE ARTERY } & \multirow{2}{*}{$\begin{array}{c}\text { UTERINE ARTERY } \\
\text { ED NOTCH }\end{array}$} \\
\cline { 2 - 4 } & RI & PI & S/D & $71.43 \%$ \\
\hline Sensitivity & $85.71 \%$ & $85.71 \%$ & $85.71 \%$ & $95.70 \%$ \\
\hline Specificity & $86.02 \%$ & $88.17 \%$ & $84.95 \%$ & $55.56 \%$ \\
\hline Positive Predictive Value & $31.58 \%$ & $35.29 \%$ & $31.58 \%$ & $97.80 \%$ \\
\hline Negative Predictive Value & $98.77 \%$ & $98.80 \%$ & $98.77 \%$ & \\
Sensitivity of RI & $:$ & $85.17 \%$ & \\
Sensitivity of PI & $:$ & $85.17 \%$ & \\
Sensitivity of S/D Ratio & $:$ & $85.17 \%$ & \\
Sensitivity of ED Notch & $:$ & $71.43 \%$ & \\
Positive Predictive value of RI & $:$ & $31.58 \%$ \\
Positive Predictive value of PI & $:$ & $35.29 \%$ & \\
Positive Predictive value of S/D Ratio: & $31.58 \%$ & \\
Positive Predictive Value of ED Notch: & $55.56 \%$
\end{tabular}

\section{Discussion}

In this prospective study conducted in Andhra medical college, King George Hospital for one year, the outcomes of the study, the predictive values of various Doppler indices have been discussed.

The incidence of hypertension is $15 \%$, the incidence of Pre-eclampsia is $7 \%$, the incidence of gestational hypertension is $8 \%$, IUGR $10 \%$.

The prevalence of Pre-eclampsia was $7 \%$ which was similar to that quotedby Bewley et al., ${ }^{5} 1991$ (4.6\%) and Iron et al. ${ }^{6}, 1998$ (4\%). Prevalence of SGAless than 10 percentile was $10 \%$, similar to that quoted by North et at, ${ }^{7} 1994$ (6.6\%).
Majority of the pregnant ladies selected are in the age group of $21-25$ years( $48 \%$ ), followed by $\leq 20$ years $(23 \%), 26-30$ years $(22 \%)$ and $\geq 31$ years $(7 \%)$ in that order.

The youngest pregnant woman observed in this study is 18 years, and the oldest is 33 years.

The average age of the pregnant women in the study is 24 years.

Among 100 study population, 53 were primigravida, the incidence being $53 \%$ and the Second gravida were 30 (30\%), 17 (17\%) being Multi gravida. Most of the study population were primigravida. 
Figure 1 : Age Distri Bution

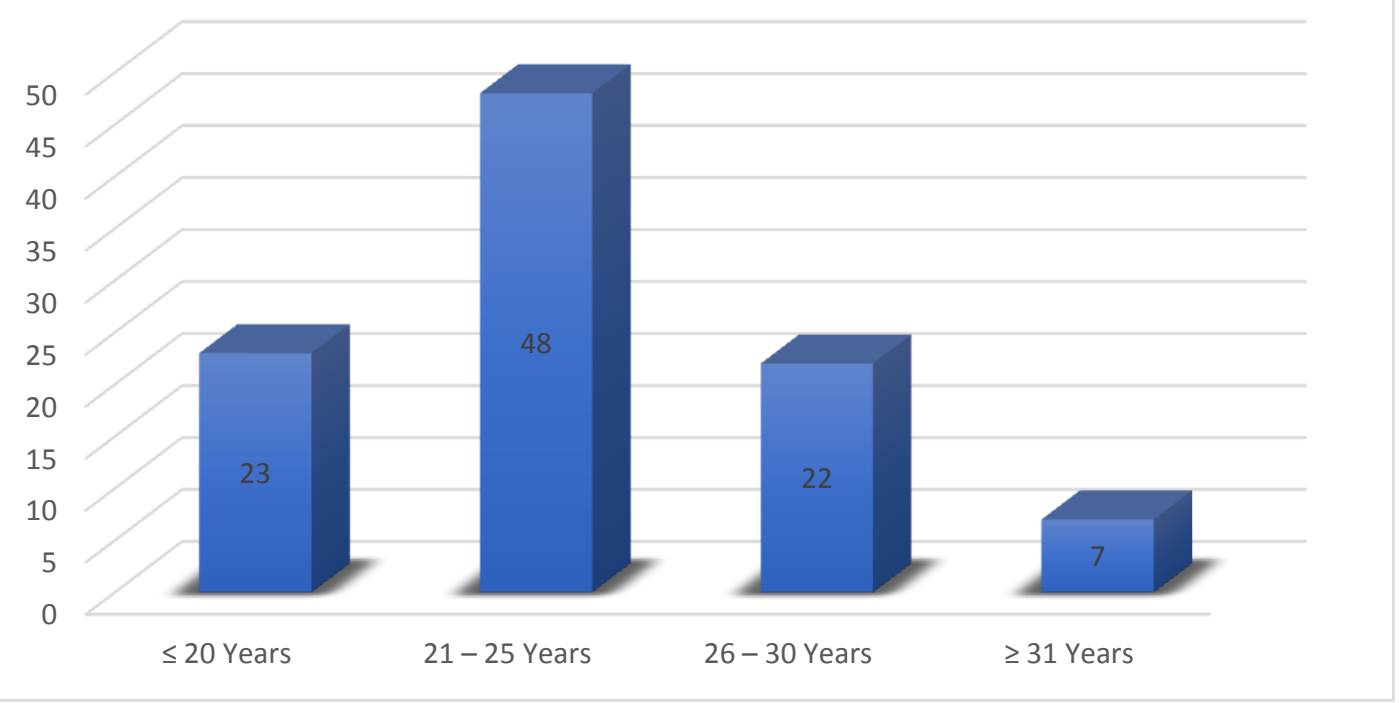

Hypertension was noted in $15(15 \%)$ of the 100 pregnant women, of which 8 are primigravida, 4 are second gravida and 3 are multigravida.
Pre-eclampsia was noted in $7(7 \%)$ of the 100 pregnant women, of which 3 are primigravida, 2 are second gravida and 2 are multigravida.

Figure 2 : Frequency of Hypertension And Pre-Eclampsia

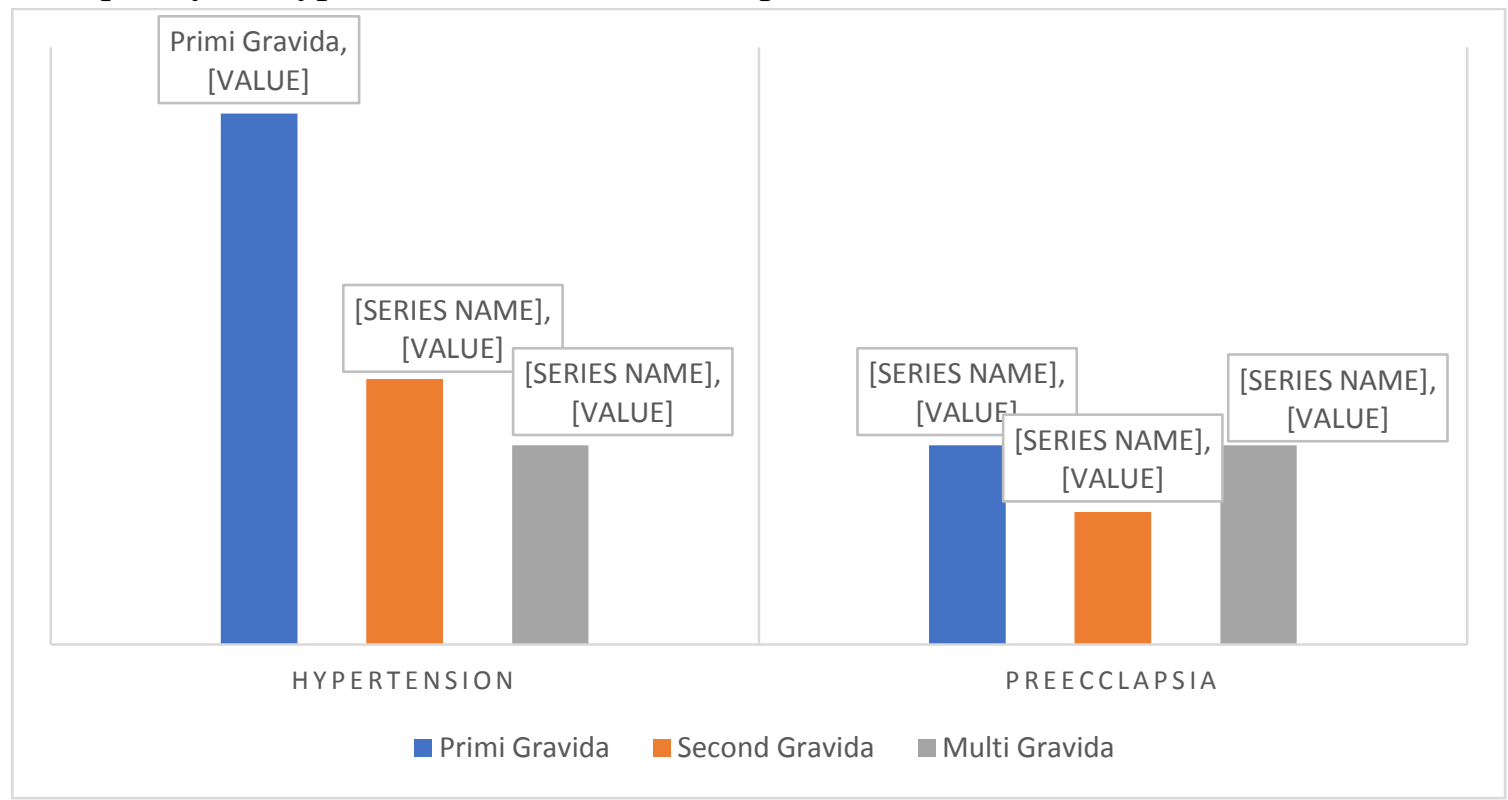

In the routine urine examination, 7 pregnant women had proteinuria in the course of pregnancy.

In 100 pregnant women who were included in study 70 of pregnant women had Vaginal Delivery (70\%), 18 of pregnant women had Emergency LSCS (18\%), and 12 of patients had Elective $\operatorname{LSCS}(12 \%)$.
Among 21 pregnant women of abnormal Doppler, 18 pregnant women were induced, of which 7 pregnant women had vaginal Delivery (33\%), 10 pregnant women went for emergency LSCS (48\%), and 4 pregnant women went for Elective LSCS (19\%). 
Figure 3 : Type of Delivery

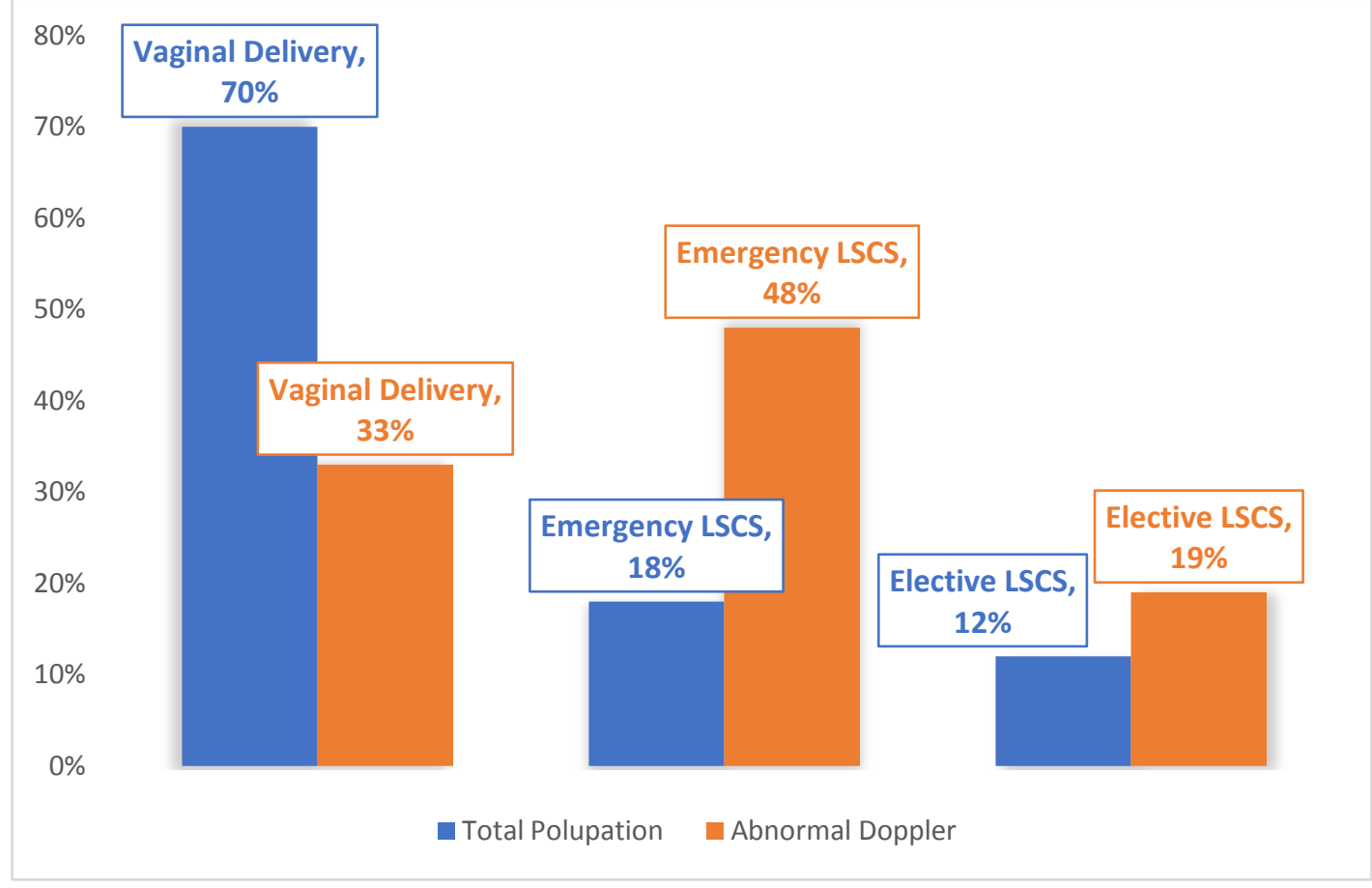

Among the 100 pregnant ladies selected in the study, the mean gestational age of delivery is 38.33 weeks with earliest being 34 weeks and last being 41 weeks.

Highest deliveries were conducted at 39 and 40 weeks of gestation (29\% each).

Among the 100 babies delivered 83 babies are term deliveries (87\%) and 17 are pre-term deliveries (17\%).

The mean birth weight of 100 babies delivered is $2.92 \mathrm{kgs}$ with maximum birth weight being 3.8 $\mathrm{kgs}$ and minimum birth weight being $2.0 \mathrm{kgs}$. Low birth weight babies are $21(21 \%)$.

Among the 100 pregnant women under study 10 developed IUGR of which 7 are preterm IUGR (7\%), and 3 are term IUGR (3\%).

Out 100 babies delivered 12 babies are admitted into NICU (12\%) with a maximum stay of 22 days and a minimum stay of 1 day.

Among the 100 pregnant women under study, only 6 pregnant women showed abnormal doppler in First-trimester when 95th percentile is taken as cut off. Among them 6 had abnormal RI, 5 had an abnormal PI,and 6 had an abnormal S/D ratio.

Of the 6 pregnant women who had abnormal Doppler in First-trimester 4 developed pre- eclampsia with a sensitivity of $57.17 \%$ for RI, $57.14 \%$ for PI and $57.17 \%$ for S/D ratio.

The Specificity being $97.85 \%$ for RI, $98.92 \%$ for PI and $97.85 \%$ for S/D ratio.

The Positive predictive value of RI is $66.67 \%$, of $\mathrm{PI}$ is $80.00 \%$ and that of $\mathrm{S} / \mathrm{D}$ ratio is $66.67 \%$.

The Negative predictive value of RI is $96.81 \%$, of $\mathrm{PI}$ is $96, .84 \%$ and that of S/D ratio is $96.81 \%$.

Among the Doppler parameters considered in First-trimester in the study, all have the same sensitivity and PI has the highest specificity and positive predictive value.

Among the 100 pregnant women under study, only 19 pregnant women showed abnormal doppler in second-trimester when 95th percentile is taken as cut off. Among them 19 had abnormal RI, 17 had abnormal PI, 19 had abnormal S/D ratio, and 9 showed an early diastolic notch.

Of the 19 pregnant women who had abnormal Doppler in second-trimester 6 developed preeclampsia with a sensitivity of $85.71 \%$ for RI, $85.71 \%$ for PI, $85.71 \%$ for S/D ratio and $71.43 \%$ for the early diastolic notch.

The Specificity being $86.02 \%$ for RI, $88.17 \%$ for PI, $86.02 \%$ for S/D ratio and $95.70 \%$ for early diastolic notch. 
The Positive predictive value of RI is $31.58 \%$, of PI is $35.29 \%$, of S/D ratio, is $31.58 \%$, and that of the early diastolic notch is $55.56 \%$.

The Negative predictive value of RI is $98.77 \%$, of PI is $98.80 \%$, of S/D ratio, is $98.77 \%$ and that of early diastolic notch is $97.80 \%$.

Among the Doppler parameters considered in second-trimester in the study early diastolic notch has the highest specificity and RI, PI \&S/D ratio have the highest sensitivity. Early diastolic notch has the highest positive predictive value
Overall 21 pregnant women showed abnormal doppler among the 100 pregnant women selected for study, of which 6 pregnant women developed pre-eclampsia.

One pregnant woman developed pre-eclampsia without abnormal doppler. So, the sensitivity and sensitivity of abnormal Doppler in predicting preeclampsia is $85.71 \%$ and $83.87 \%$ respectively. This is similar to the result obtained by Kurdi et al..

Table 6: Comparison of study at AMC, KGH with Previous Studies On uterine Artery Doppler for PreEclampsia

\begin{tabular}{|c|c|c|c|c|c|c|c|}
\hline Author & $\begin{array}{l}\text { Outcome } \\
\text { Measure }\end{array}$ & Indicator & Prevalence & Sensitivity & Specificity & PPV & NPV \\
\hline Bewley et al.., 1991 & Pre-eclampsia & RI $>95^{\text {th }}$ centile & 4.6 & 24 & 95 & 20 & 96 \\
\hline Bower et al.., 1993 & Pre-eclampsia & RI $>95^{\text {th }}$ centile $+/$ - notch & 2.5 & 7.5 & 86 & 12 & 99 \\
\hline North et al.., 1994 & Pre-eclampsia & RI $>90^{\text {th }}$ centile & 3.3 & 27 & 89 & 8 & 97 \\
\hline Chan et al.., 1995 & Pre-eclampsia & $\mathrm{RI}>95^{\text {th }}$ centile & 6.9 & 22 & 97 & 36 & 94 \\
\hline Irionet al.., 1998 & Pre-eclampsia & S/D $>90^{\text {th }}$ centile $+/-$ notch & 4 & 26 & 88 & 7 & \\
\hline Kurdi et al...2000 & Pre-eclampsia & RI $>95^{\text {th }}$ centile & 2.2 & 62 & 89 & 11 & 99 \\
\hline Present Study at AMC & Pre-eclampsia & RI $>95^{\text {th }}$ centile & 7 & 85.71 & 83.87 & 28.73 & 98.73 \\
\hline Present Study at AMC & Pre-eclampsia & Notch & 7 & 71.43 & 95.70 & 55.56 & 97.80 \\
\hline
\end{tabular}

Results are similar to the other studies except notch has more specificity, RI is also having more predictive value as the present study was done from 22 - 26 weeks which reduces false positive rate.

\section{Conclusion}

This prospective observational study of the radiological evaluation of uterine artery Dopplershows that

$>$ Uterine artery Doppler can be used to predict pre-eclampsia in normal people who are not having risk factors.

$>$ The diastolic notch in second-trimester has the highest specificity compared to other parameters.

$>$ First-trimester doppler alone has a good predictive value in predicting pre-eclampsia.

$>$ Combination of first and second-trimester uterine artery Doppler is the best indicator of prediction of Pre-eclampsia.

Women with normal impedance to flow in the uterine arteries constitute a group that have alow-risk (negative predictive value of 96\%) of developing obstetric complications related to uteroplacental insufficiency and fetoplacental insufficiency.

> Uterine artery Doppler can be included in hospitals with facilities andinfrastructure to identify a group of patients at risk of developing Pre-eclampsia.

\section{References}

1. Aris T. Papageorghious, Christian K H. $\mathrm{Yu}$, II se E. Erasmur, Howard S. Cuckle., Kypros H. Nicolaides, Br. J. Obstet Gynaecol June 2005, vol.112 pp-707-709

2. Chappel I. Bewley S: Pre-eclamptic Toxemia. The Role of uterine artery Doppler Br. J. Obstetgynaecol 105, 379382; 1998. ACOG committee on obstetrics practice ACOG practice bulletin diagnosis and management of pre-eclampsia and eclampsia,. Number 33, January 2002,

3. Deane C, Harrington K. A practical approach to obtaining optimum 
Dopplersignals. In: Harrington K, Campbell S, editors. A colour atlas of Dopplerultrasonography in obstetrics. London: Arnold, 1995: 35-46.

4. Fitzgerald DE, Drumm JE. Non-invasive measurement of human fetal circulation using ultrasound: a new method. BMJ 1977; 2:1450-1451.

5. Bewley Susan, Cooper Derek, Campblell S. Doppler investigations of uteroplacental blood flow resistance in the second. $\mathrm{Br} \mathrm{J}$ Obstetrics \& Gynecology 1991;98;871879.

6. Oliver Irion, Jacques Masse, Jean-Claude Forest, Jean marieMoutquin. Prediction of pre-eclampsia, low birth weight for gestation and prematurity by uterine artery blood flow velocity waveforms analysis in low-risk nulliparous women British Journal of Obstetrics and Gynecology. April 1998. Vol 105 pp 402-425.

7. North RA, Ferrier CL long D, Townend K, Kincaid-smith F, Uterine artery Doppler flow velocity waveforms in the secondtrimester for the prediction of preeclampsia and fetal growth retardation. Obstet Gynaecol 1994;83;378-86.

8. Kurdi W, Campbell S, Aquilina J, England $\mathrm{P}$, Harrington $\mathrm{K}$, The role of colour Doppler imaging of the uterine arteries at 20 weeks gestation in stratifying antenatal care. Ultrasound Obstet Gynecol $1988 ; 12 ; 339-45$. 